\title{
Transaction
}

\section{Electroless Nickel Plating on Disintegrated Pulp Fibers}

\author{
Takeshi Ueno $^{* 1, * 2}$, Shohta Takemura ${ }^{* 1}$, Masahiro Simada ${ }^{* 1}$, and Takayuki Okayama ${ }^{* 2}$ \\ *1 Tokyo Metropolitan Industrial Technology Research Institute, \\ 3-6-1, Azuma-cho, Akisima, Tokyo 196-0033, Japan \\ ${ }^{* 2}$ Graduate School of Agriculture, Tokyo University of Agriculture and Technology, \\ 3-5-8, Saiwai-cho, Fuchu, Tokyo 183-8509, Japan
}

\begin{abstract}
Making pulp fiber conductive is imperative to produce conductive paper. In this study, we experimentally investigate disintegrated pulp fibers electroless plated with nickel to make the fiber conductive. In conventional electroless nickel plating on plastic materials, adding the drying process after the surface activation and catalyst adsorption processes have made electroless plating on the fiber surface possible. Our observations of the cross section of plated pulp fibers and the analysis of its elements verify that a nickel film covering the fiber surface was formed. The plate film became thicker as the plating time and temperature increased. The DC electrical resistance of the plated pulp fiber decreased to $10^{1} \Omega$, as the plating time and temperature increased. The AC impedance was converged between $10^{1} \Omega$ and $10^{2} \Omega$ as the measurement frequency increased, which verifies that conductivity can be maintained.
\end{abstract}

(Received 5 May, 2011; Accepted 1 July, 2011)

\section{Introduction}

Paper has a low electrical conductivity because of its actual nature. It is be more conductive when mixed with carbon fiber or metallic material or when its surface becomes conductive with the plating process. This type of paper with conductivity is one of the function papers called conductive paper [1-5]. Conductive paper is mainly used for electromagnetic shielding or static electricity elimination. For electromagnetic shielding, the surface conductivity must be $10^{\circ} \mathrm{S} \cdot \mathrm{sq}$ or smaller with a high conductivity of paper. For static electricity elimination, it must be between $10^{-12} \mathrm{~S} \cdot \mathrm{sq}$ and $10^{3} \mathrm{~S} \cdot \mathrm{sq}[6]$.

Electromagnetic shielding is one of the important properties required to suppress electromagnetic noise from the electronic equipment. This suppression of noise is one of the measures taken to meet the EMC (Electromagnetic Compatibility) requirements. In EMC requirements, the electronic equipment cannot malfunction under an influence from external noises (immunity from external noises), and at the same time, it cannot emit noise (emission of electromagnetic noises) that may influence other types of equipment. Such electronic equipment as information equipment and medical equipment must meet EMC requirements. The electronic equipment is subjected to immunity and emission tests that are internationally standardized and regulated $[7,8]$. The immunity test verifies that the equipment has robustness against electromagnetic noise while the emission test verifies that the equipment does not emit large electromagnetic noise. Equipment may emit large electromagnetic noise exceeding the limit or it may malfunction in response to an external noise. In such cases, the equipment must be modified to include the countermeasure against the large emission of noise or the susceptibility to external noise. Parts or electromagnetic shielding material can be added and the circuit design can be modified.

Shielding materials are conductive so that the electric field component of the electromagnetic wave can be shielded. Shielding materials are largely grouped into metallic, conductive film, conductive composite, conductive surface processing, and conductive adhesive materials, whereas conductive paper is a type of a conductive film material [9]. These shielding materials placed to fill gaps on the cabinet or housing may also be attached on the surface of the electronic circuit.

Conductive paper comprising conductive materials is light in weight and has sufficiently high flexibility to conform to any form. Examples of conductive paper commercially available include conductive sheets manufactured by applying the paper-making technology to the conductive fiber [10] and conductive paper coated with thin metallic material on both sides [11]. Following types of conductive paper have been studied.

(i) Conductive paper produced by applying the paper- 
making technology to the mixture of carbon and pulp fibers [12]. Because the carbon fiber has a conductivity lower than that of metallic materials, the surface resistivity of this type of paper is as high as several $\mathrm{mS} \cdot \mathrm{sq}$ and it cannot function as an electromagnetic shielding material.

(ii) Conductive paper is made by applying the papermaking technology to the mixture of pulp and polyester fibers wherein the metallic film is deposited on the surface by the electroless plating [13]. The refractory property of this type of paper may be insufficient in such an application as the suppression of electromagnetic wave emission from the electronic circuit board on which the CPU is mounted. The temperature of the CPU may rise to approximately $70^{\circ} \mathrm{C}[14]$

(iii) On the surface of the proposed conductive paper, the metallic film will be deposited by electroless plating [15]. In the electroless plating process, a paper has to react electrochemically with the plating solution in the plating bath, and for plating a paper of a large size, the bath has to be larger than the paper size. While using this type of conductive paper in practical applications, we often find problems of the paper not being sufficiently flexible to conform to any form because of the metallic film formed on the surface.

In this paper, we propose a new process to produce highly flexible conductive paper that can shield electromagnetic noise. In the first step of the process, pulp is disintegrated into each fiber. Each of the disintegrated fibers is coated with nickel (hereinafter, plated pulp fiber) by plating its surface by electroless nickel plating. Raw (i.e., unplated) and plated pulp fibers are then mixed to make conductive paper.

In this study, we attempt to identify relationships between the plated pulp fiber (i.e., raw material for conductive paper), film thickness, and electrical characteristics. We use the conventional electroless nickel plating technique [16] and the two-layer plating of copper /nickel in conductive paper [17]. For simplicity and clarity in electrical evaluation, we also use a single layer plating of nickel in the experiment.

\section{Experimental}

\subsection{Trial to make plated pulp fiber \\ 2.1.1 Pulp fiber}

As a raw pulp fiber, we used a soft wood bleached craft pulp fiber, Nadelholz Bleached Kraft Pulp (NBKP), because it features a longer fiber length than the hard wood pulp fiber, and conductive paper made from NBKP exhibits better electrical characteristics than that made from the hard wood pulp fiber.

\subsubsection{Plating material}

We used the plating solution, SUMER S-680 of Japan Kanigen Co., in the electroless nickel plating. A plating film formed with this solution is of the nickelphosphorous (Ni-P) alloy [18], whose crystal structure is known to be amorphous [19]. nickel-boron (Ni-B) alloy can also be used in the electroless nickel plating but the $\mathrm{Ni}-\mathrm{P}$ film shows better corrosion resistance than the Ni-B film [20].

\subsubsection{Plating process}

Figure 1 illustrates the process flow in this study and Table 1 shows conditions in each step. Pulp fibers were disintegrated into one each fiber and each of the disintegrated fibers was plated. Such a process comprises the sensitizing process to sensitize the fiber surface with the tin chloride solution, the activating process to adsorb the palladium catalyst on the surface, and the plating process to plate the surface with a nickel film.

The disintegration and electroless plating processes were conducted in liquids such as water or plating solutions. In the preliminary experiment, the pulp fiber electroless plated by the conventional process results in poor plating film quality. We postulate that because the sensitizing and activating solutions are not adsorbed on the surface in the sensitizing and activating processes, respectively, it was impossible to form a good quality film on the surface [21].

In the actual experiment, we added a drying process after the sensitizing and activating processes to accelerate the adsorption of solutions on the pulp fiber.

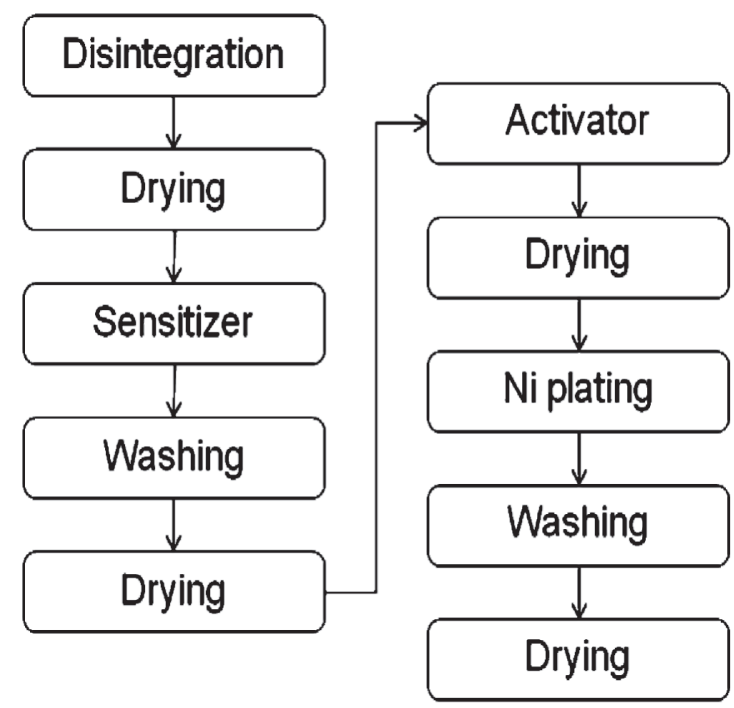

Fig. 1 Plating process. 
Table 1 Process conditions.

\begin{tabular}{|c|c|}
\hline Process & Process condition \\
\hline Disintegration & In compliance to JIS P 8220 \\
\hline Drying & $\begin{array}{l}\text { Drying temperature } 105^{\circ} \mathrm{C} \text {, Drying } \\
\text { period of } 30 \mathrm{~min}\end{array}$ \\
\hline $\begin{array}{l}\text { Sensitizing } \\
\text { process }\end{array}$ & $\begin{array}{l}\text { Immerse test piece }(0.2 \mathrm{~g}) \text { in a five } \\
\text { times diluted solution }(300 \mathrm{~mL}) \text { of } \\
\text { PINK SUMER (Japan Kanigen } \\
\text { Co. Composition: } \mathrm{HCl}, \mathrm{SnCl}_{2} \text {. } \\
\mathrm{H}_{2} \mathrm{O} \text { etc. ) and agitate the solution } \\
\text { for } 10 \text { min at the room } \\
\text { temperature. }\end{array}$ \\
\hline Washing & $\begin{array}{l}\text { Immerse test piece }(0.2 \mathrm{~g}) \text { in pure } \\
\text { water }(300 \mathrm{~mL}) \text {, agitate the water } \\
\text { for } 10 \mathrm{~min} \text { at room temperature, } \\
\text { and remove the test piece out of } \\
\text { the water. }\end{array}$ \\
\hline $\begin{array}{l}\text { Activating } \\
\text { process }\end{array}$ & $\begin{array}{l}\text { Immerse test piece }(0.2 \mathrm{~g}) \text { in ten } \\
\text { times diluted solution }(300 \mathrm{~mL}) \text { of } \\
\mathrm{RED} \text { SUMER (Japan Kanigen } \\
\left.\text { Co. Composition: } \mathrm{HCl}, \mathrm{PdCl}_{2} \text { etc. }\right) \text {, } \\
\text { and agitate the solution for } 10 \mathrm{~min} \\
\text { at room temperature. }\end{array}$ \\
\hline Plating process & $\begin{array}{l}\text { Immerse test piece }(0.2 \mathrm{~g}) \text { in ten } \\
\text { times diluted solution }(300 \mathrm{~mL}) \text { of } \\
\text { the plating solution, } \mathrm{S}-680 \text { (Japan } \\
\text { Kanigen Co. Compositions: } \\
\left.\mathrm{NiSO}_{4} \cdot 6 \mathrm{H}_{2} \mathrm{O}, \mathrm{NaH}_{2} \mathrm{PO}_{2} \cdot \mathrm{H}_{2} \mathrm{O} \text { etc. }\right) \\
\text { and agitate the solution for } 1,2,5 \text {, } \\
\text { and } 10 \text { min at } 45^{\circ} \mathrm{C}, 60^{\circ} \mathrm{C} \text {, and } \\
75^{\circ} \mathrm{C} \text {, respectively. }\end{array}$ \\
\hline
\end{tabular}

\subsection{Evaluation of plating film}

\subsubsection{Observation of surface and cross section}

We observed the surface and cross section of the plated pulp fiber by using the scanning electron microscope (SEM : JSM-6460LV of JEOL Ltd.). We also analyzed elements of the plating film by using energy dispersive X-ray spectroscopy (EDX: Falcon CDU of EDAX), which is an accessory of the SEM. The plated pulp fiber was imbedded into a resin and the resin was cut out in the direction normal to the fiber length. We then polished and observed the cutting plane.

\subsubsection{Plating film thickness of plated pulp fiber}

We pictured the cross section of the fiber using the SEM and measured the film thickness. For the film thickness, we used the smallest measurement.

\subsubsection{Electrical resistance}

We measured the DC electric resistance in the plated pulp fiber by using the 4-terminal measurement configuration multimeter (34401 A of Agilent Technologies ) and jigs. Such a measurement configuration was commonly used to measure the conductance of highly conductive materials [22]. The
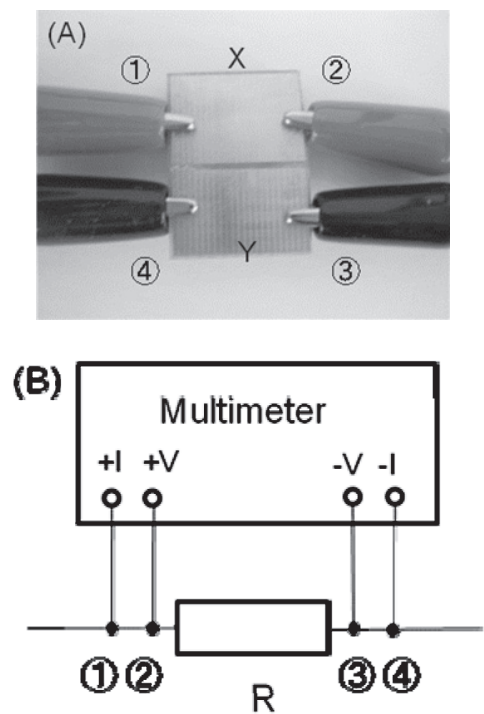

Fig. 2 Electrical resistance measurement jig (A) Jig, (B) Electrical circuit.

measurement could eliminate an influence from the contact resistance between the fiber and the electrode as well as an influence from the cable electrical resistance, allowing an accurate electric resistance measurement of raw materials. Figure 2 shows the jigs and electrical circuit used for the measurement. The plated pulp fiber was placed such that it will straddle the space between upper (X) and lower (Y) electrodes. Space between electrodes is $500 \mu \mathrm{m}$.

We measured the AC impedance with the precision impedance analyzer (4294A of Agilent Technologies). We also measured the impedance of the test piece with the same jigs used in the electric resistance measurement. We then measured the AC impedance between $100 \mathrm{kHz}$ and $100 \mathrm{MHz}$.

\section{Results and discussion}

\subsection{Plating film profile and its elements}

\subsubsection{Observation with SEM}

Figure 3 shows SEM images of the pulp fiber and plated pulp fiber surfaces on which the plating film is formed. The plated pulp fiber surface was not even but is plated.

Figure 4 shows SEM images of the plated pulp fiber cross section and nickel distribution on the cross section. Nickel was distributed on the same area as the plating film area imaged with SEM. We indentify that the film was composed of nickel.

\subsubsection{Elemental analysis with EDX}

Figure 5 shows a distribution of elements analyzed with EDX in the pulp and plating film on the plated pulp 


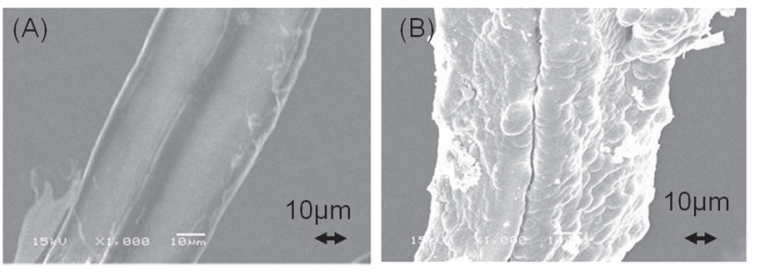

Fig. 3 Fiber surface.

(A) Pulp fiber (B) Pulp fiber plating

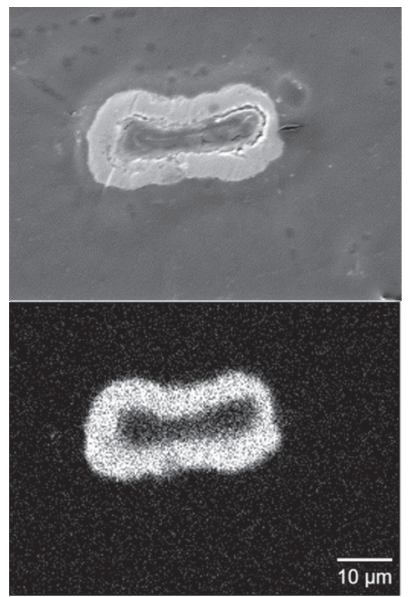

Fig. 4 Ni distribution of the pulp fiber plating. Top : SEM image, Bottom : Ni distribution

(A)

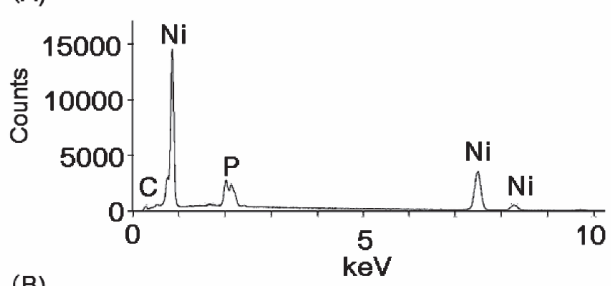

(B)

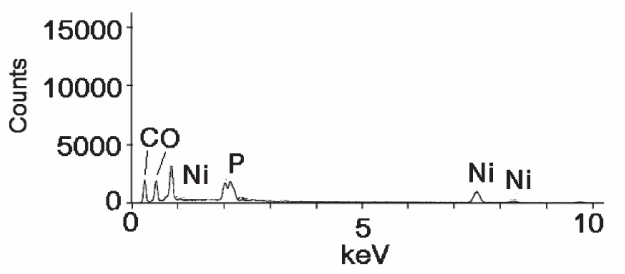

Fig. 5 Elemental analysis of pulp fibers coated. (A) Plating area, (B) Fiber core

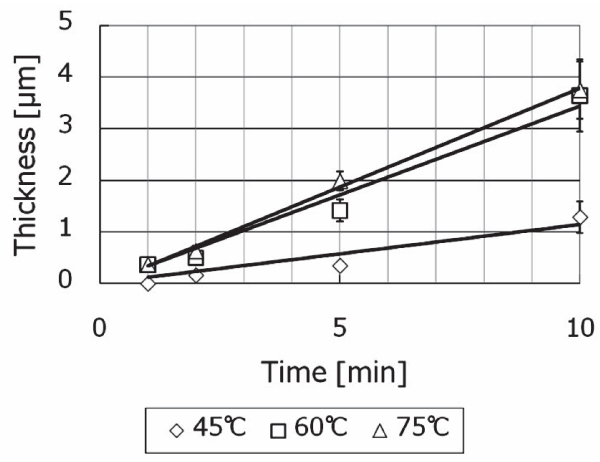

Fig. 6 Relationship between plating thickness and plating conditions. cross section. Figure 5 (B) shows elements on the pulp fiber cross section, indicating that carbon (C) and oxygen (O) were originally present in the pulp. As shown in Fig. 5 (A), nickel (Ni) and phosphorus (P), originally present in the plating material, were detected in the plating film. We verify that the plating film was a $\mathrm{Ni}-\mathrm{P}$ alloy.

We believe that nickel, as shown in Fig. 5 (B), is mixed when the pulp and the film are polished to make the test piece for the cross section observation.

\subsection{Plating condition and film thickness}

Figure 6 shows the relationship between film thickness and plating conditions (i.e., plating time), indicating that the film becomes thicker as the plating time increases. Because electroless nickel plating was a catalytic reaction, the film thickness increases as the plating time increases until the plating material was depleted. In this experiment, we also obverse such a trend of increase.

It is reported [23] that, in electroless nickel plating, the film thickness will be doubled when the plating temperature increases by $10^{\circ} \mathrm{C}$. Also in this experiment, the film becomes approximately three times thicker at $60^{\circ} \mathrm{C}$ than it was at $45^{\circ} \mathrm{C}$. But no distinctive differences in the thickness were observed between $60^{\circ} \mathrm{C}$ and $75^{\circ} \mathrm{C}$. The amount of hydrogen generated when the pulp fiber was immersed in the plating bath increases as the temperature increases. Hydrogen prevents nickel ions supplied on the pulp fiber surface from moving. We postulated that such a prevention of the ion movement retards the progress of plating reaction in the region where the temperature exceeds $60^{\circ} \mathrm{C}$. A conductive plated pulp fiber of $9.6 \mathrm{~g}$ was prepared using the raw pulp fibers of $0.2 \mathrm{~g}$ in this condition.

\subsection{Plating condition and electrical resistance}

Figure 7 shows the relationship between the plating condition and electrical resistance in the plated pulp fiber,

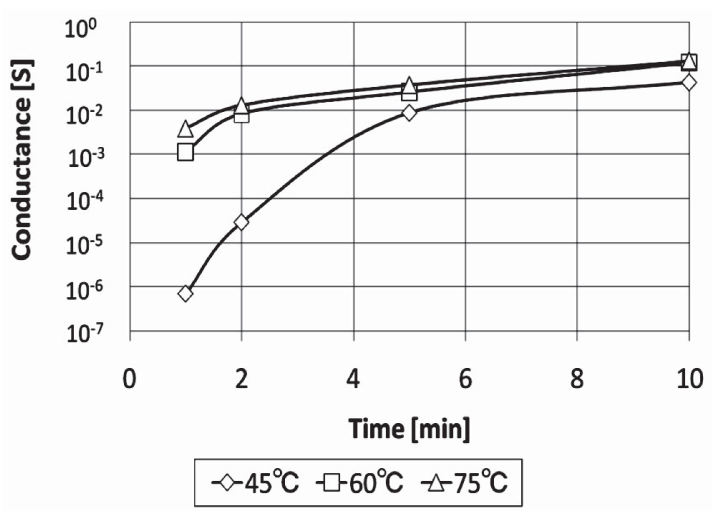

Fig. 7 Relationship between electrical conductance and plating conditions. 
indicating that the DC electrical resistance decreases as the plating temperature and time increase. But no distinctive differences in the electrical resistance were observed between $60^{\circ} \mathrm{C}$ and $75^{\circ} \mathrm{C}$ of the plating temperature.

Figure 8 shows the relationship between the film thickness and conductance in the metallic film, indicating that the conductance increases linearly and is inversely proportional to the film thickness.

The equation below is proposed to express the relationship between the conductance and plating film cross section [24].

$$
\mathrm{G}=\sigma \times \mathrm{S} / \mathrm{L}
$$

Here, $\mathrm{G}=$ conductance, $\sigma=$ volume conductivity, $\mathrm{S}=$ cross sectional area of the plating film, and $\mathrm{L}=$ length of the fiber. Because the cross sectional area of the plating film is proportional to the square of the film thickness, this equation can indicate that the conductance $(G)$ is proportional to the square of the film thickness.

Results showed that the conductance of the plated pulp fiber can be controlled by the plating temperature and time.

Figure 9 shows the AC impedance of the plated pulp decreases as the plating time increases. However, the fiber at $75^{\circ} \mathrm{C}$ for several plating times, indicating that the impedance is not affected by the frequency ranging from a low frequency to $1 \mathrm{MHz}$ but remains fairly constant. In cases the frequency is $1 \mathrm{MHz}$ or more, the impedance decreases when the time is $1 \mathrm{~min}$, whereas it increases when the time is $10 \mathrm{~min}$. One of the components that exhibit a behavior similar to this is a lead-type resistor used in an electronic circuit [25]. When a resistor has high resistance, the capacitive component between wirings becomes prominent in the resistor impedance.

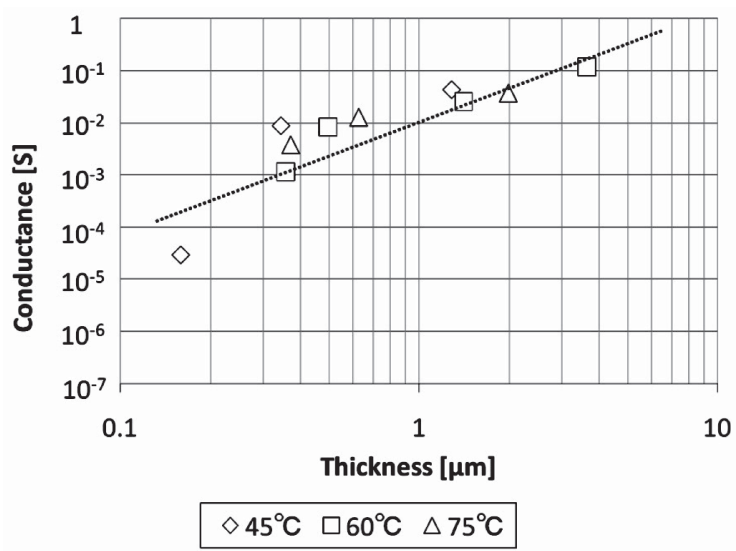

Fig. 8 Relationship between electrical resistance and the plating thickness.

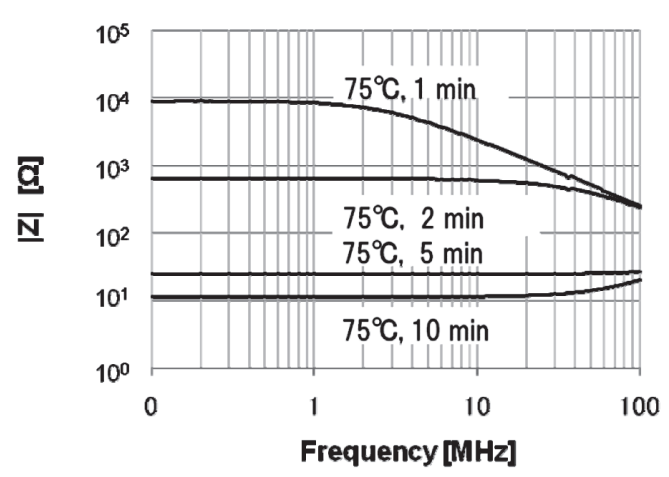

Fig. 9 AC impedance of the coated fiber pulp.

When it has low resistance, the inductive component in wirings becomes prominent in the resistor impedance. We postulate that the impedance in the plated pulp fiber exhibits the same behavior. This experiment indicates that the impedance is converged between $10^{1} \Omega$ and $10^{2} \Omega$ at $100 \mathrm{MHz}$, showing that the electrical conductivity can be maintained even at a higher frequency.

It will be possible to produce flexible conductive papers by mixing the plated pulp fibers with the raw pulp fibers. Details on these results will be reported in the near future.

\section{Conclusions}

To make the pulp fiber conductive, we disintegrate pulp into one each fiber and experimentally investigate the surface of the disintegrated fiber electroless plated with nickel.

The electroless plating is made possible by inserting the drying process after the disintegration, activating, and sensitizing processes in the plating process. Our observations of the plated pulp fiber cross section and analysis of its elements verify that a nickel film covering the pulp fibers is formed.

The plate film becomes thicker as the plating time and temperature increase.

The DC conductance of the plated pulp fiber increases to $10^{-1} \mathrm{~S}$, as the plating time and temperature increase.

The AC impedance decreases as the plating time increases. The impedance is constant from low frequency to $1 \mathrm{MHz}$, and above such a frequency region, the impedance converges between $10^{1} \Omega$ and $10^{2} \Omega$. We verify that conductivity can be maintained.

We discover that electroless nickel plating is an effective process to make the pulp fiber conductive; furthermore, we postulate that the conductance of the plated pulp fiber can be controlled by the plating temperature and time. 


\section{References}

1. H. Inagaki, Sen'i Gakkaishi, 46, 195 (1990).

2. H. Inagaki, Sen'i Gakkaishi, 50, 427 (1994).

3. K. Fujiwara, Kami Pa Gikyoushi, 49, 160 (1995).

4. K. Kuboshima, Sen’i Gakkaishi, 48, 527 (1992).

5. K. Kuboshima, Kami Pa Gikyoushi, 43, 1085 (1989).

6. Y. Kudo, Sen'i Gakkaishi, 44, 487 (1988).

7. IEC, “International Standard CISPR 22," Japanese Standards Association, 6th edition, (2008).

8. "JIS Handbook: Electromagnetic compatibility (EMC)," Japanese Standards Association, (2009).

9. Y. Shimizu, Kougyo Zairyo, 42, 18 (1994).

10. M. Yokokawa and I. Watanabe, Kougyo Zairyo, 37, 69 (1989).

11. H. Furuichi, Kougyo Zairyo, 37, 74 (1989).

12. T. Oya, T. Ogino, Carbon, 46, 169 (2008).

13. S. Shinagawa, Y. Kumagai, and K. Urabe, J. of Porous Matterials, 6, 185 (1999).

14. T. Kobayashi, Nippon Kikai Gakkai Ronbunshu, 64, 4185 (1998).

15. S. Takemura, T. Ueno, M. Shimada, and $T$. Okayama, Proc. of the $6^{\text {th }}$ Int. Conf. on Mater. for Resour (2009).
16. Electro-plating Society, "Text book for plating", THE NIKKAN KOGYO SHIMBUN, LTD., p221 (1986).

17. S. Shinagawa, Kami Pa Gikyoushi, 42, 131 (1988).

18. Electro-plating Society, "Fundamentals and applications of electroless plating", THE NIKKAN KOGYO SHIMBUN, LTD. (1994).

19. K. Masumoto and T. Watanabe, "Amorphous plating technique and its application," THE NIKKAN KOGYO SHIMBUN, LTD., p198 (1990).

20. Reference 18), p. 254

21. T. Ueno et al., Autumn meeting - Sen'i Gakkai, 65, 48 (2010).

22. T. Nakazawa, "Electric and Electronic Materials," Corona Publishing Co., Ltd., p145 (2005).

23. T. Kadoya, "Functions and Engineering of New Paper," Shokabo Publishing Co., Ltd., p30 (2001).

24. N. Ichinose, "Electric and Electronic Functional Materials," Ohmsha Ltd., p61 (2003).

25. T. Kawai, Design Wave Magazine, CQ Publishing Co., Ltd., p59 (April 2000). 